\title{
THE BRIDGE OVER THE ADDA RIVER IN BRIVIO: HISTORY, FULL-SCALE TESTING AND FE MODELLING
}

\author{
GIACOMO ZONNO ${ }^{1 *}$, CARMELO GENTILE ${ }^{1}$ \\ ${ }^{1}$ Department of Architecture, Built environment and Construction engineering (DABC) \\ Politecnico di Milano, Piazza Leonardo da Vinci 32, 20133 Milan, Italy \\ e-mail: giacomo.zonno@polimi.it (*corresponding author), carmelo.gentile@polimi.it
}

Keywords: Reinforced Concrete Arch Bridge, Operational Modal Analysis, Finite Element Modeling and Updating, Non-Destructive techniques.

\begin{abstract}
Selected results from the investigation program of a historic R.C. bridge are presented in the paper. The bridge, crossing the Adda river between the Municipalities of Brivio and Cisano Bergamasco, consists of three tied arch spans, about $44.0 \mathrm{~m}$ length each, and represents a crucial node for the vehicular traffic of the region. After a maintenance intervention performed on one pier, the local Authorities committed to Politecnico di Milano an extensive investigation including: (i) documentary research and review of the bridge history; (ii) visual inspection and geometric survey of each span; (iii) full-scale load tests and ambient vibration tests; (iv) FE modelling of each span and validation of the numerical models (through comparison with the available experimental results) and (v) structural assessment of the bridge in its present condition. After a concise review of the bridge history, the paper summarizes the complete results of the experimental tests performed on one span (visual inspection, geometric survey, full-scale load tests and dynamic tests) as well as the development of numerical models.
\end{abstract}

\section{INTRODUCTION}

Historic bridges are an important part of the national heritage and often represent essential nodes of the contemporary road and railway network. A great number of historic reinforced concrete (R.C.) arch bridges was erected in Italy in the first half of the 20th century, as the concrete arch was the most common solution adopted for bridges spanning over $40.0 \mathrm{~m}$ or more [1]. Of course, many of these bridges, which were designed according to what today are considered outdated code regulations, are still in service, and their structural assessment is of increasing concern. As a matter of fact, these structures require a special attention because are exposed to several potential damage causes, such as aging of the materials, effects of pollution, lack of maintenance, inappropriate use, increase of traffic vibrations and natural hazards.

The procedure to assess the structural condition of a historic bridge involves several tasks, according to the multidisciplinary approach presented in the modern guidelines of restoration and conservation of historic structures [2]: documentary research in the archives, on-site fullscale testing and finite element (FE) modelling are some of these important tasks to track the health state of a historic structure [3-4]. The documentary research can provide useful 
information about the construction phases, structural details and any changes that may have occurred in the life of the structure. Direct inspection and on-site full-scale tests can provide information about the current state and can increase the knowledge about the material properties and the actual structural response. FE models based on the original design drawings, geometric survey and on-site tests can play a fundamental role in the correct assessment of the investigated structures [5-7]. Moreover, the process of developing FE models involves assumptions and simplifications (about the boundary conditions, the characteristics of materials, the presence of damaged areas, etc.) that may induce remarkable errors in predicting the actual response of a "as-built" bridge. Even refined FE models often fail to predict resonant frequencies and modes shapes with a sufficient level of accuracy, as a consequence of both modelling and material uncertainties. A good practice to reduce the gap between the actual behaviour of a full-scale structure and its model is to perform operational modal testing and the consequent validation/calibration of the numerical model by minimizing a measure of the difference between experimental and numerical parameters [1].

Within this context, the present paper summarizes the investigation carried out on the Brivio bridge, built in 1917 and consisting of three R.C. tied arch spans. The investigation involves documentary research, visual inspection and geometric survey, load tests and ambient vibration tests, FE modelling and model updating. The paper is structured as follows. Section 2 describes the main characteristics of the Brivio bridge. Section 3 describes the experimental investigations carried out to assess the heath state of the analysed bridge. Section 4 describes the implemented FE models in detail and section 5 concludes the paper.

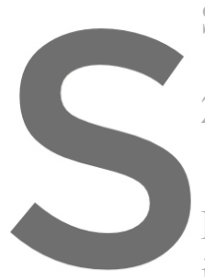

2 DESCIIPTION OH

The historic Brivio Bridge is located Lecco) and of Cisano B in the Lombardia region, northern Italy.
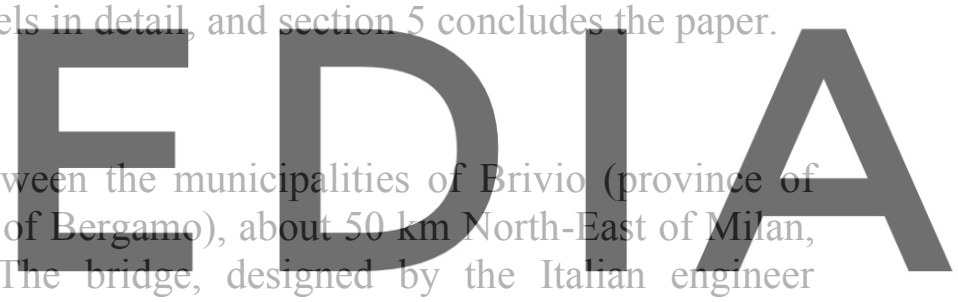
Giuseppe Banfi [8], was built between June 1912 and May 1917 (Fig. 1) and crosses the Adda

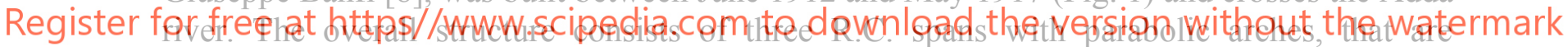

supported by two piers - whose foundation is built in the river bed - and two end abutments.

The documentary research in the archives allowed to find almost complete information on the bridge design, so that important data are available through original drawings (Fig. 2a), static calculation of the arches (Fig. 2b), structural details of reinforcement and foundation system (Fig. 2a), construction materials and code regulation adopted in the bridge design [9].
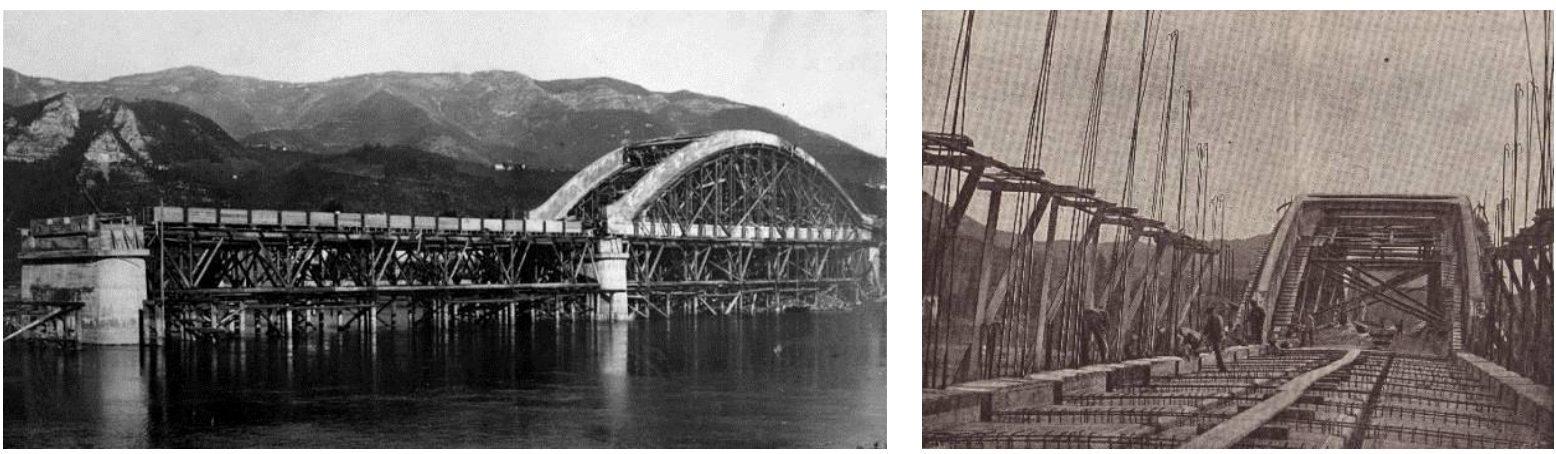

Figure 1: Pictures of the construction phases of the Brivio bridge. 
(a)

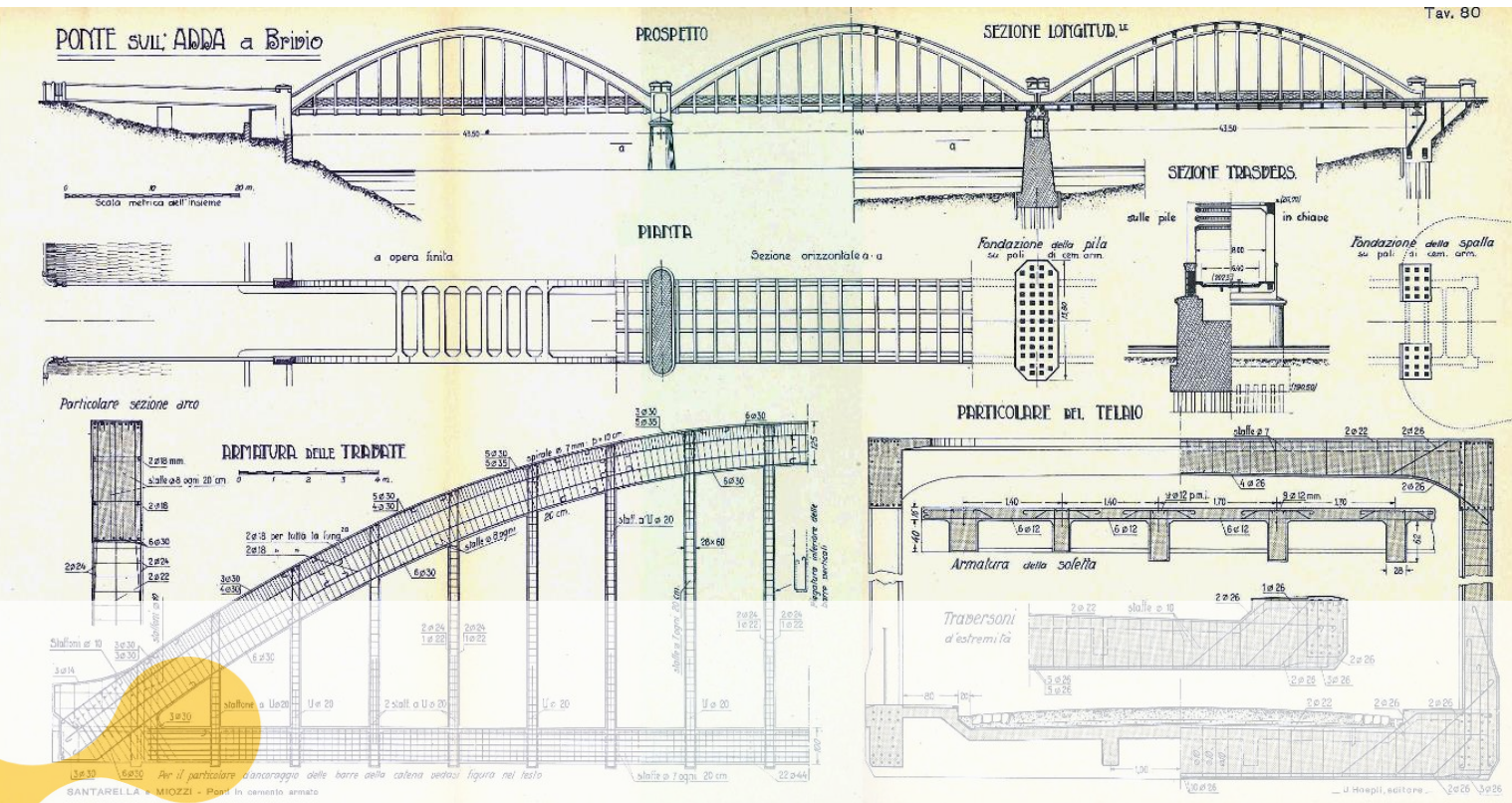

(b)

\section{PONTE SULL' ADDA A BRIVIO}
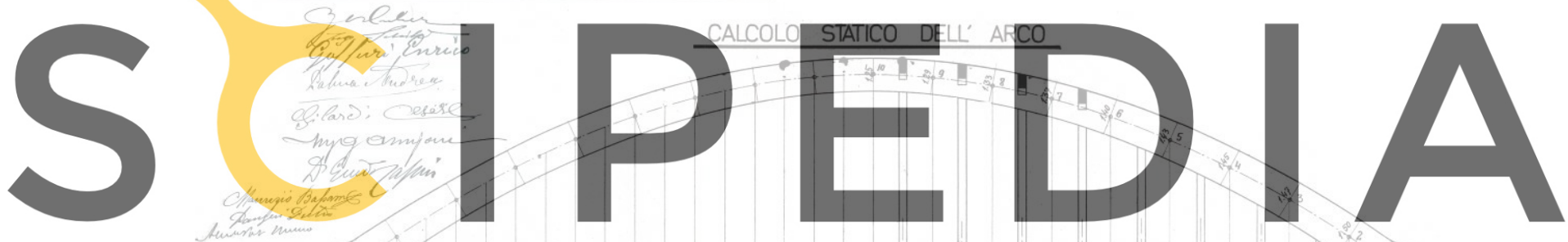

Register for free at https//www.scipedia.com to download the version without the watermark

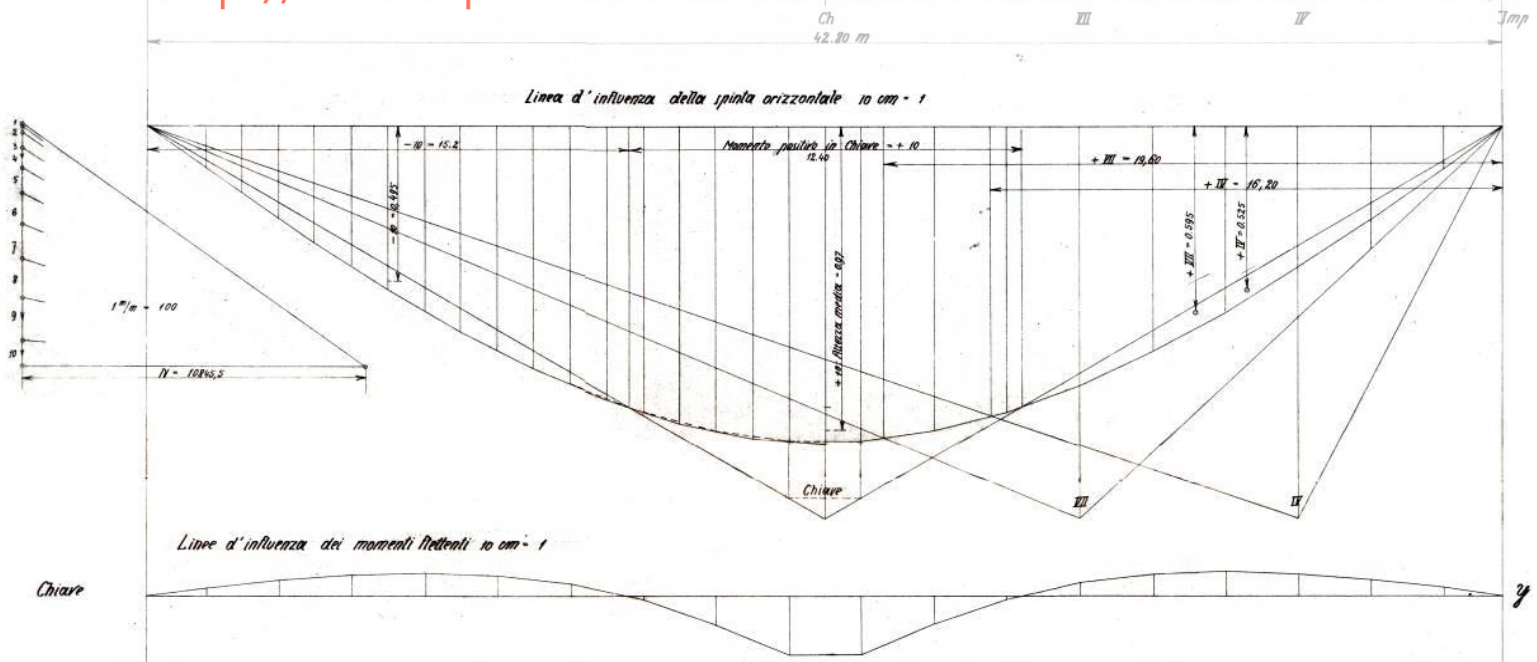

Figure 2: Brivio bridge: (a) Original design drawings [8], and (b) Static calculation of the arch. 
In particular, design documents revealed that the steel bars were designed for a maximum tension of $100 \mathrm{MPa}$, whereas the maximum compression in the concrete was set equal to 4 $\mathrm{MPa}$ (with the exception of a few cross-sections where a higher compression of $7 \mathrm{MPa}$ was assumed as allowable). The documentary research also provided information on the issues met during the construction and especially related to the search of workmen and raw materials in some periods of the First World War and the proof load test performed before the bridge opening.

An upstream front view of the bridge is shown in Fig. 3. The Cisano Bergamasco (Bergamo) side is on left bank, whereas Brivio (Lecco) side on the right bank. In this paper, the closest span to Bergamo side was identified as Span 01, the central span as Span 02, and the closest span to Lecco side as Span 03.
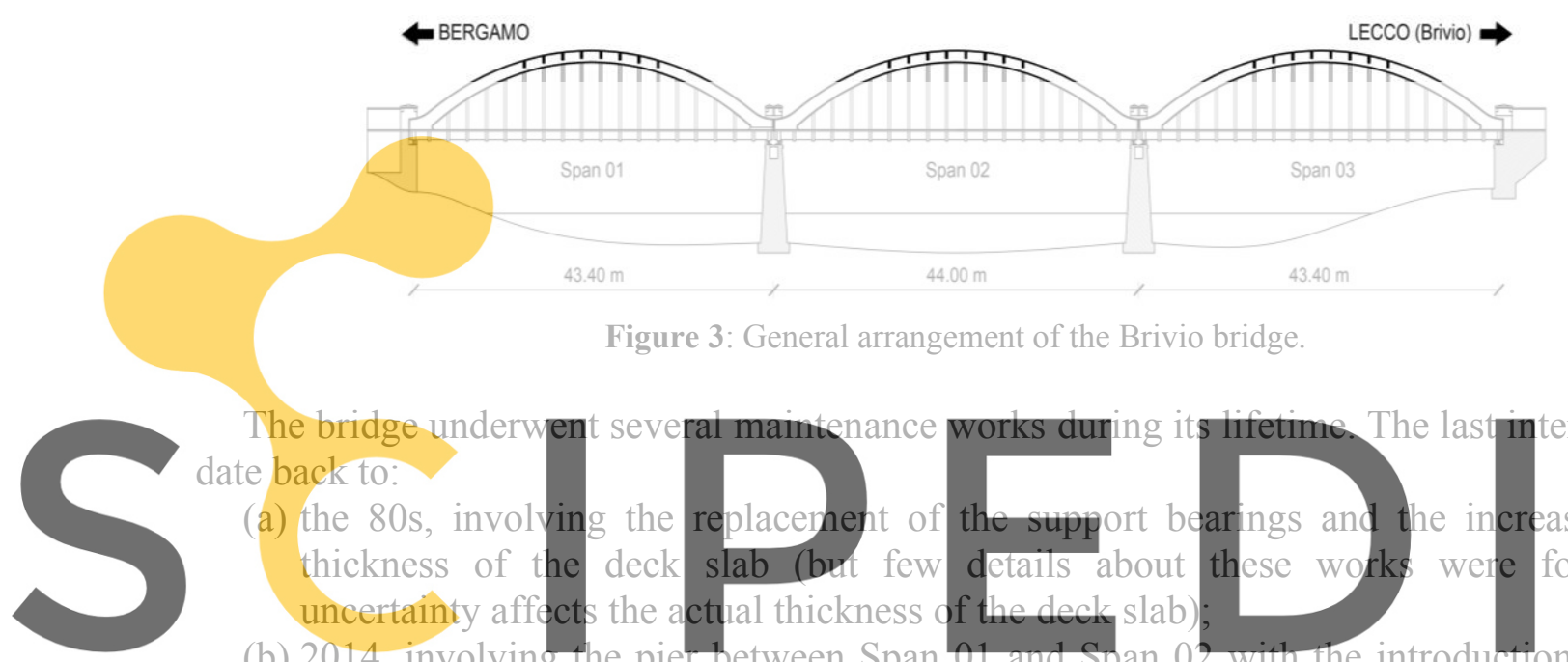

The bridge underw date back to:

(a) the $80 \mathrm{~s}$, involvin thickness of the deck uncertainty affect

(b) 2014, involving t
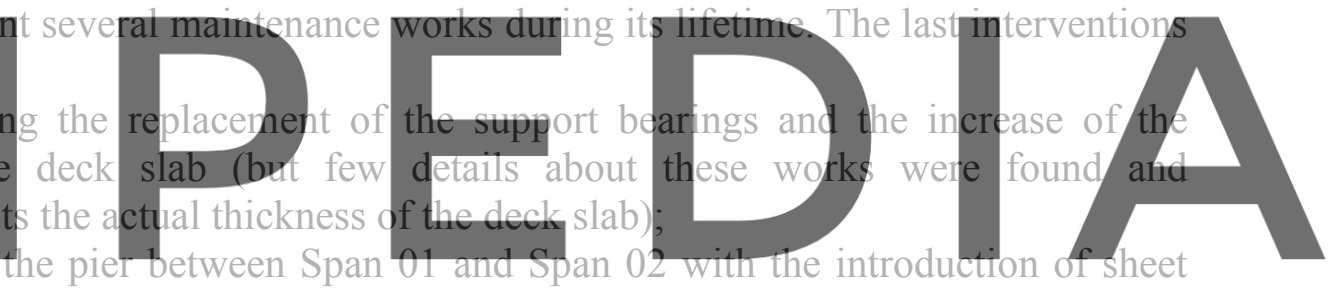

piles to protect it against the erosive action of water.

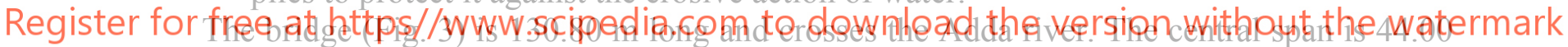

$\mathrm{m}$ long while the length of lateral spans is $43.40 \mathrm{~m}$. Each span is symmetric with respect to its mid-iongitudinal plane and consists of a horizontal deck, 2 arches and 32 vertical hangers (1 arch and 16 hangers per side).

The deck, $9.2 \mathrm{~m}$ wide, hosts two roadway lanes (each $3.8 \mathrm{~m}$ wide) and two sidewalks (Fig. 4a) and it is composed by a concrete slab supported by a grid of longitudinal and transversal beams. The deck cross section includes two main girders $\left(0.45 \times 1.00 \mathrm{~m}^{2}\right)$ and two secondary longitudinal beams $\left(0.20 \times 0.40 \mathrm{~m}^{2}\right)$; the girders are spaced $8.60 \mathrm{~m}$ center to center and includes $22 \phi 44$ steel bars of reinforcement, whereas the secondary beams are spaced $2.00 \mathrm{~m}$ center to center. Both elements (girders and beams) are symmetrically located with respect to the vertical longitudinal plane of the bridge (Fig. 4d). The R.C. slab was originally $14 \mathrm{~cm}$ thick, but after the strengthening of the $80 \mathrm{~s}$, even if no drawings are available, the owner reports the increase to $20 \mathrm{~cm}$. However, the R.C. slab is also supported by transversal beams, equally spaced every $2.30 \mathrm{~m}$ (in correspondence of each vertical hanger).

The arches exhibit a rise of about $8.00 \mathrm{~m}$ at the keystone and a rectangular cross section, $0.60 \mathrm{~m}$ wide and of height varying between $1.25 \mathrm{~m}$ and $1.50 \mathrm{~m}$. The arches of each span are transversally connected with eight struts of $0.35 \times 0.50 \mathrm{~m}^{2}$ section (Figs. $4 \mathrm{~b}$ and $4 \mathrm{c}$ ). 
Two concrete tapered piers support the deck into the river bed. Each pier, with a maximum dimension at the base of $3.80 \times 12.80 \mathrm{~m}^{2}$ (Fig. 4a), is supported by forty-eight piles of "Considère" type, ranging from $13.00 \mathrm{~m}$ to $16.00 \mathrm{~m}$ in depth.

During the visual inspection, the concrete of the bridge shows diffuse whitish efflorescence and clear signs of carbonation. Furthermore, some horizontal cracks were observed in the vertical R.C. hangers (Fig. 4e).

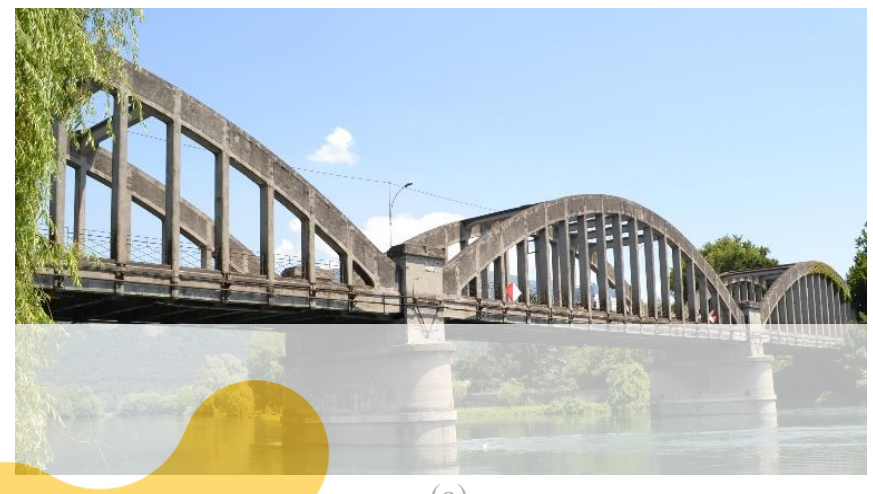

(a)

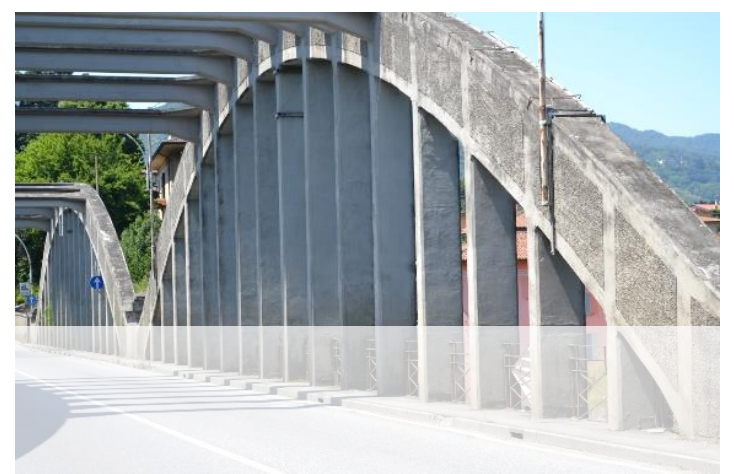

(b)

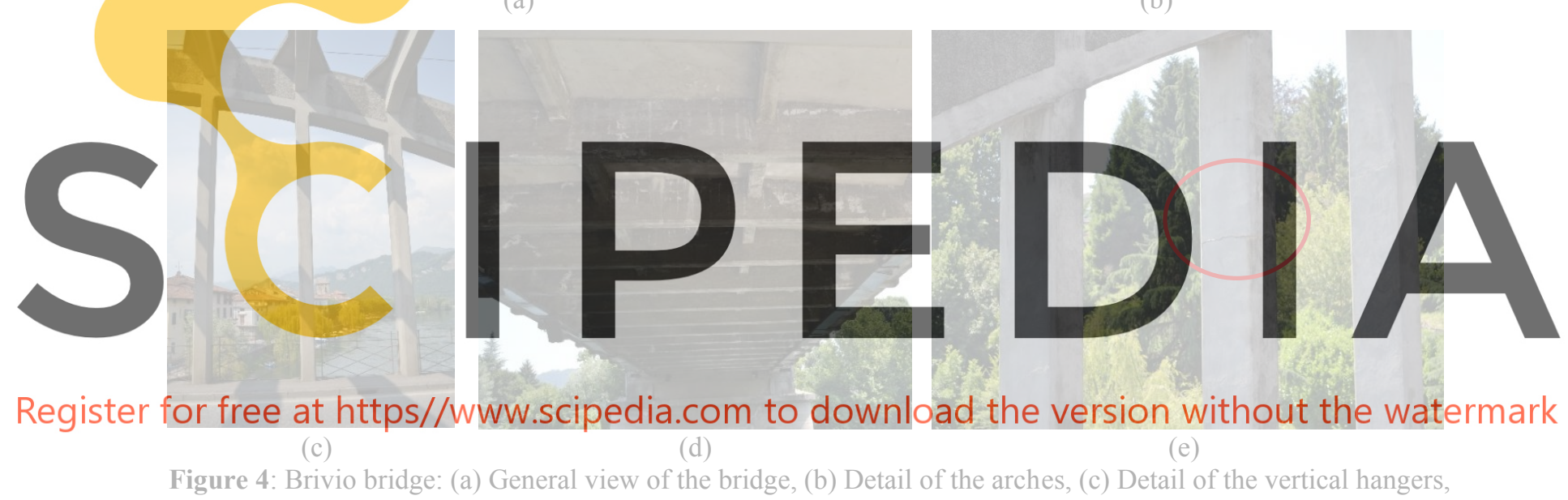

(d) Detail of the longitudinal beams, and (e) View of one horizontal crack detected on a hanger.

\section{TESTING AND SYSTEM IDENTIFICATION OF THE BRIDGE}

Direct inspection and experimental tests were carried out to assess the bridge current state. Most of those tests were performed on June 2014 (i.e. geometrical survey of arches and hangers, visual inspection and ambient vibration tests) whereas static load tests were performed on September 2014. The experimental investigation was carried out for all the spans of the bridge [10], but in the present paper only the results of the Span 01 will be described.

In the case of ambient vibration tests (AVT), the structural response to ambient and operational excitation was acquired with sixteen vertical measuring positions according to the sensors layout shown in Fig. 5a. Eight cross-sections were instrumented in correspondence of the vertical hangers with two accelerometers placed on both sides of the deck. Two different setups were carried out, considering two sensors as reference transducers, which were kept at the same locations in both setups (see the blue arrows in Fig. 5a). For each setup, ten high- 
sensitivity uniaxial accelerometers (WR 731A, $10 \mathrm{~V} / \mathrm{g}$ sensitivity and $\pm 0.50 \mathrm{~g}$ measuring range) connected to a WR P31 power unit/amplifier (Fig. 5b) and a multi-channel acquisition system with 3 DAQ modules (NI 9234, 24-bit resolution, $102 \mathrm{~dB}$ dynamic range and antialiasing filters) were used. The structural response was acquired at a sampling frequency of $200 \mathrm{~Hz}$ and a sampling time of $7200 \mathrm{~s}$.

The modal identification was carried out applying the Frequency Domain Decomposition (FDD) technique [11], and the first four singular value lines (SV) of the Span 01 are shown in Fig. 5c. In the frequency range $2-18 \mathrm{~Hz}$, seven vibration modes were identified, and the corresponding mode shapes are shown in Fig. 6. In particular, $f_{1}, f_{2}, f_{4}$ and $f_{6}$ are bending modes, while $f_{3}, f_{5}$ and $f_{7}$ are torsion modes.

The load test was carried out on September $8^{\text {th }}, 2014$ and a Topcon GPT 3003 total station (angle measurement accuracy of 0.3 mgon and maximum distance measurement of $3000 \mathrm{~m}$ ) was used to measure the vertical displacement of selected points of the bridge during the tests. Two two-axle trucks (average weight of $336 \mathrm{kN}$ ) and two three-axle trucks (average weight of $434 \mathrm{kN}$ ) were used as test vehicles.
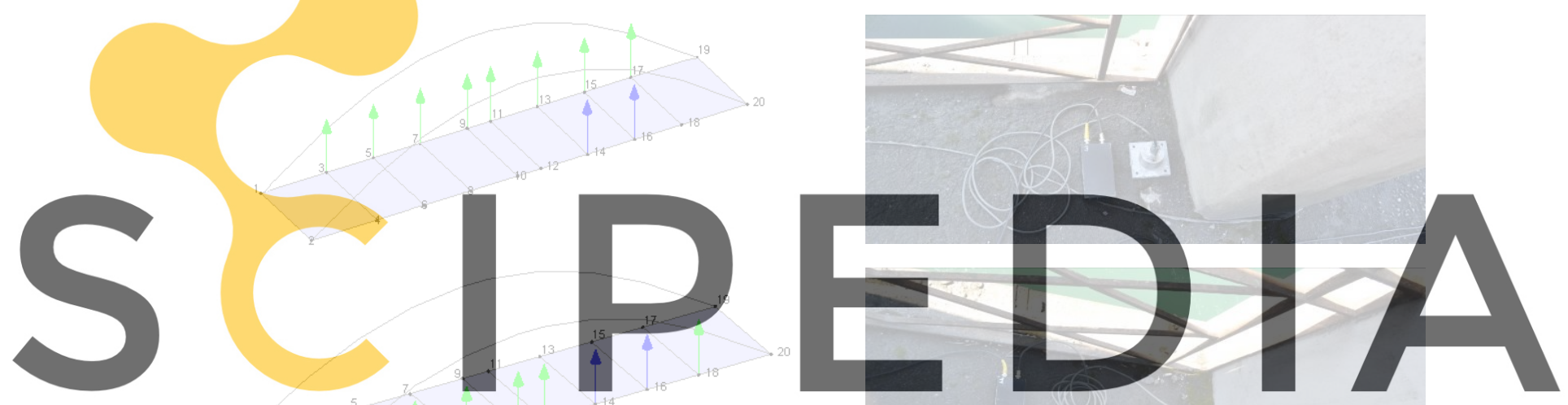

Register for free at https//www.scipedia.com to download the version without the watermark

(a)

(b)

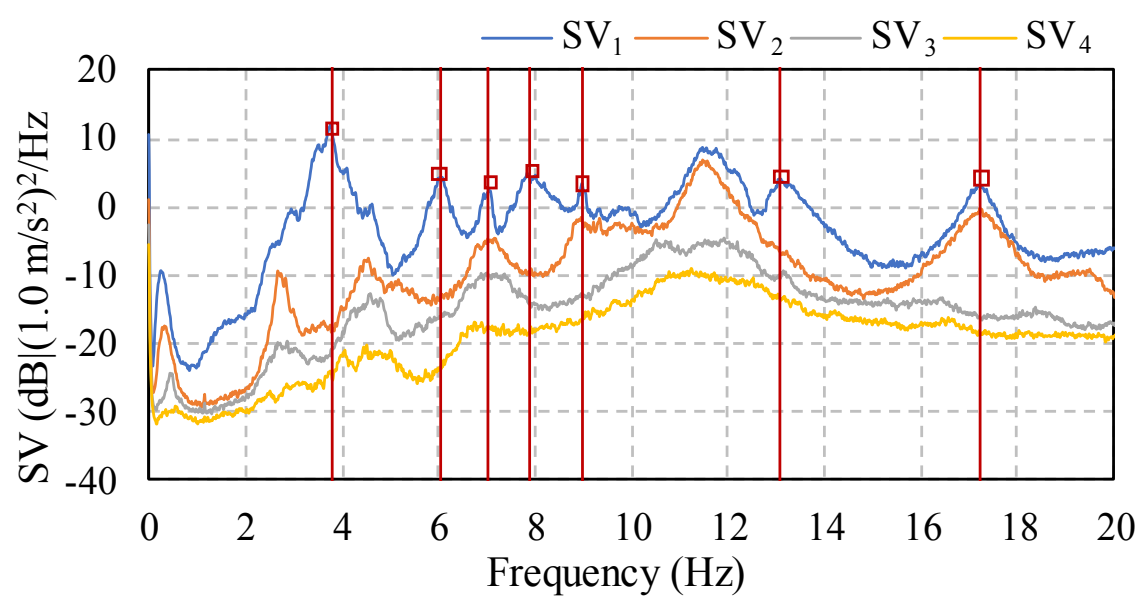

(c)

Figure 5: Ambient vibration test: (a) Sensors layout, (b) WR 731A accelerometer and WR P31 amplifier, and (c) Singular value lines (SV) and identification (FDD) of resonant frequencies of Span 01. 


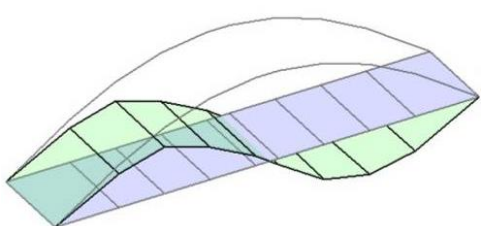

$f_{1} \exp =3.77 \mathrm{~Hz}$

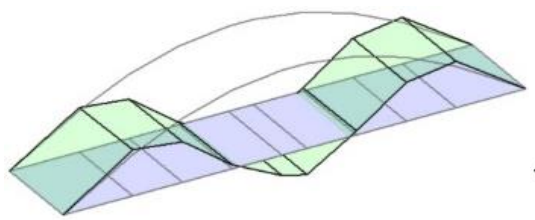

$f_{4} \exp =7.87 \mathrm{~Hz}$

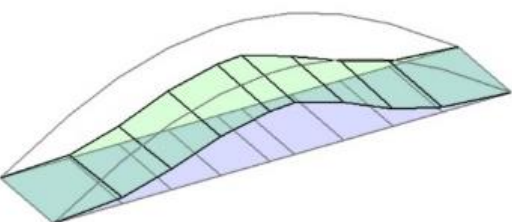

$f_{2}^{\exp }=6.03 \mathrm{~Hz}$

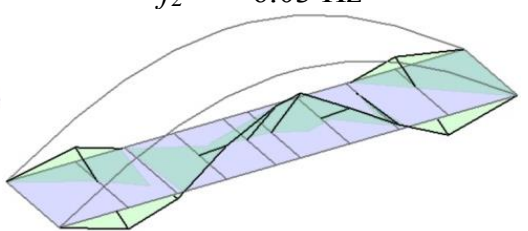

$f_{5} \exp =8.97 \mathrm{~Hz}$

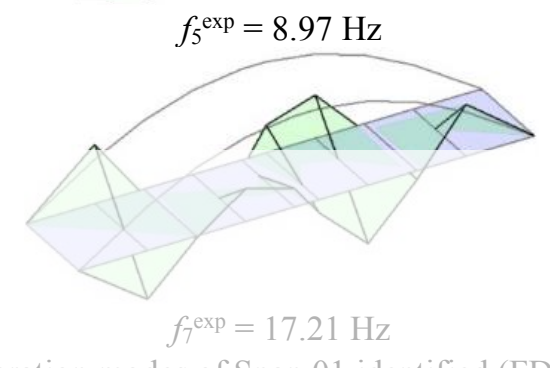

$f_{7} \exp =17.21 \mathrm{~Hz}$

Figure 6: Vibration modes of Span 01 identified (FDD) from AVT.

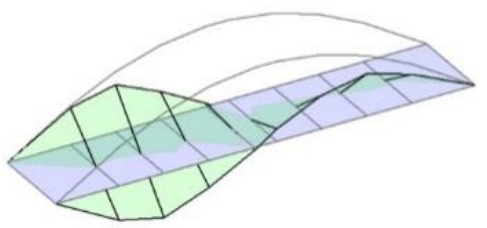

$f_{3} \exp =7.02 \mathrm{~Hz}$

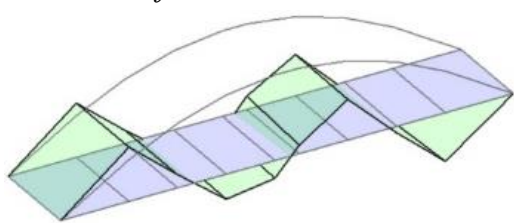

$f_{6} \exp =13.10 \mathrm{~Hz}$
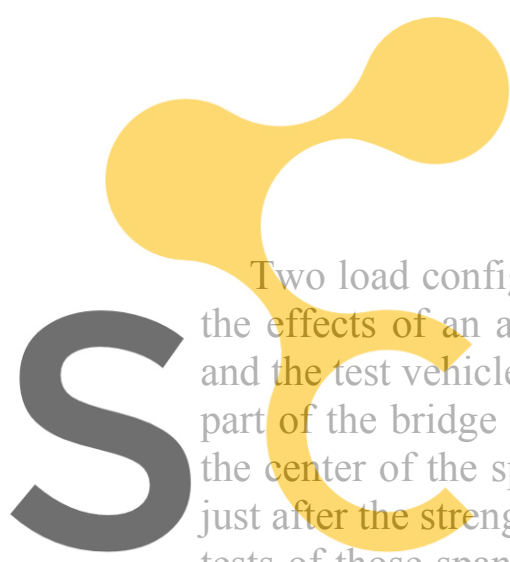

Two load configurations were carried out. The first configuration is aimed at investigating the effects of an almost uniformly distributed load along the longitudinal axis of the bridge and the test vehicles were positioned in one row, with the three-ax part of the bridge (Fig. 7). The second configuration consists in the center of the span along two parallel rows (Fig. 8b). Since just after the strengthening of the pier (on Bergamo side) suppo

tests of those spans involved both load conditions, whereas only the first one was adopted in testing Span 03.

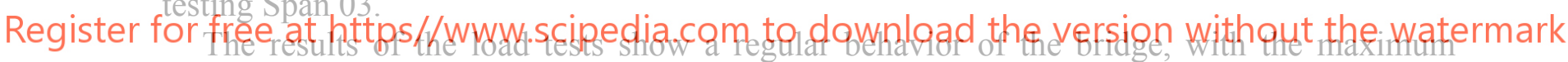
displacements being very low (i.e., less than ten thousandth of the span length). Figure 8c shows the deformed shape of Span 01 under the load condition characterized by two rows of test vehicles: the loaded span exhibited a maximum vertical displacement of $3.2 \mathrm{~mm}$.

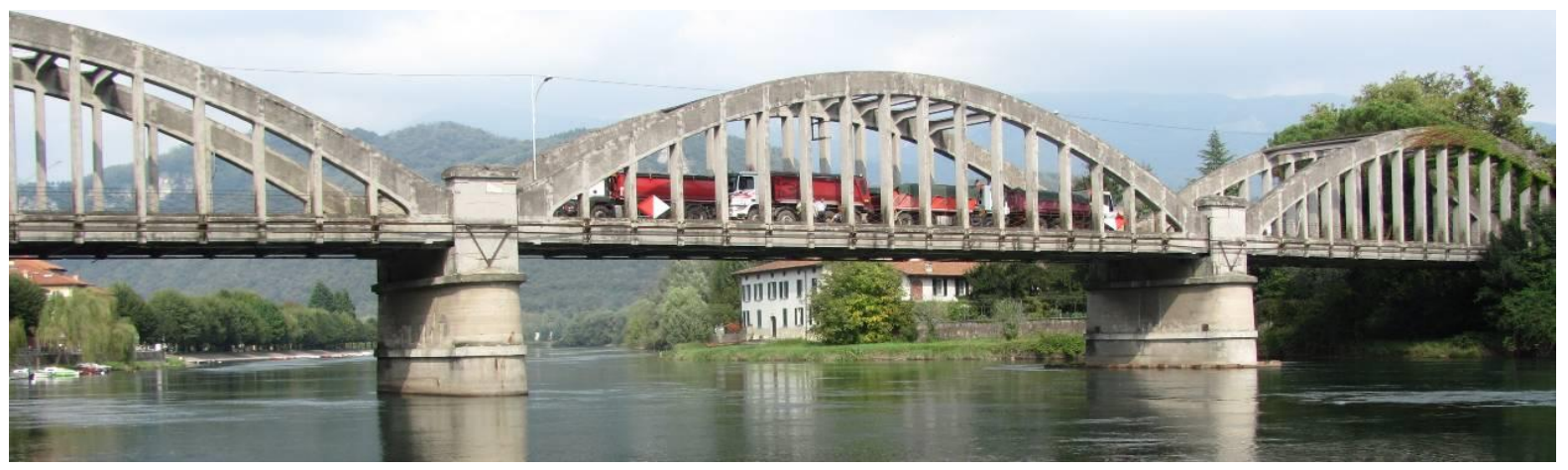

Figure 7: Trucks used during the load test of Span 02. 
(a)

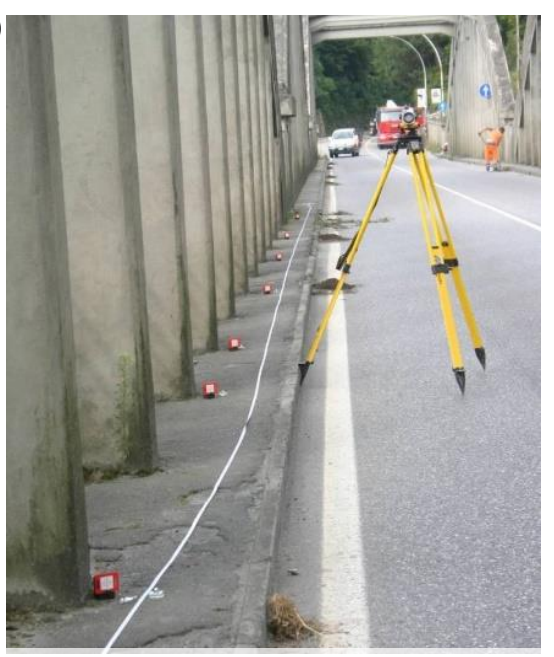

(b)

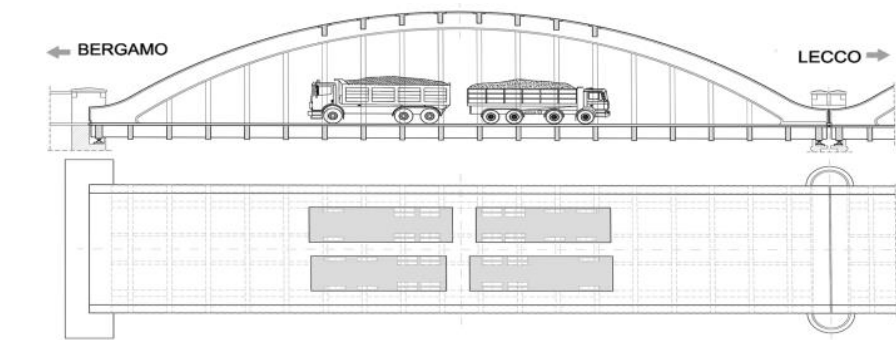

(c)

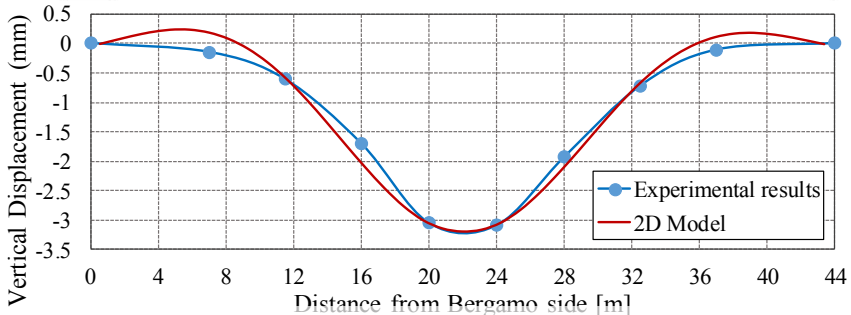

Figure 8: Load tests: (a) View of the bridge during the tests; (b) Second load configuration of Span 01; (c) Deformed shape of Span 01 and comparison with the prediction of 2D model.

\section{FEM MODELLING AND UPDATING}

The experimental program of field tests was complemented by the development of 2D (Fig.9a) and 3D (Fig.9b) FE models, based on the available geometric survey.

The simplified 2D model was developed and, subsequently, calibrated with the results of

the AVT with the main

displacements during

developed to better inv

structure and the interventions thatiave partial

The numerical 2D model consists of 126 lin
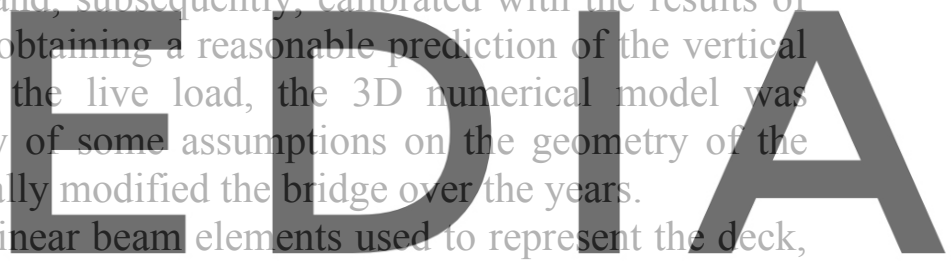

the arches and the vertical hangers (Fig.9a). The deck was simulated with a horizontal beam

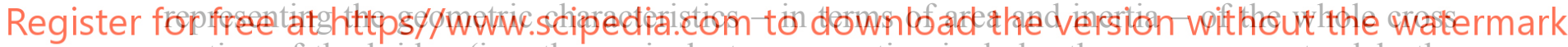
section of the bridge (i.e., the equivalent cross-section includes the upper concrete slab, the main girders and the secondary longitudinal beams). Seventeen tapered beam elements were used to model the arch: the rectangular cross section is $1.20 \mathrm{~m}$ width (equal to the sum of the width of the two side arches) and exhibits varying heights (the height decreases from the end to the top of the arch and vice versa). The sixteen hangers were simulated as vertical beams with a rectangular cross section. Furthermore, only one end of the deck was restrained to the horizontal translation, while springs were added to account for the vertical deformability of the pier and of the abutment supporting the span.

The weight per unit volume was assumed equal to $25 \mathrm{kN} / \mathrm{m}^{3}$ for the entire structure, and the Poisson's ratio of 0.20 was also held constant. The masses of the elements whose axes lie out of the plane of the model (namely, the floor beams of the deck and the transversal struts connecting the arches) have been lumped at the corresponding nodal positions.

The Young's moduli of deck $\left(E_{\text {deck }}\right)$, arches $\left(E_{\text {arch }}\right)$ and hangers $\left(E_{\text {hanger }}\right)$ and the constant of the vertical springs $\left(k_{\mathrm{s}}\right)$ were considered as uncertain parameters and their value were estimated by minimizing the difference between numerical and experimental natural frequencies. The simple system identification procedure proposed in [12] was used to solve the inverse problem. According to [12], each natural frequency of the model is approximated 
by a simple polynomial expression $f_{i}^{*}(\boldsymbol{X})$, depending on the uncertain parameters (or updating parameters) collected in the vector $\boldsymbol{X}$. After a few FE runs needed to evaluate the polynomials $f_{\mathrm{i}}^{*}(\boldsymbol{X})$, the updating parameters are computed by minimizing the following objective function:

$$
J(\boldsymbol{X})=\sum_{i=1}^{M} w_{i}\left[f_{i}^{\mathbf{e x p}}-f_{i}^{*}(\boldsymbol{X})\right]^{2}
$$

where $w_{\mathrm{i}}(i=1,2, \ldots, M)$ are weighting constant (which were set equal to 1 in the present case) and $f_{\mathrm{i}}{ }^{\mathrm{exp}}$ represents the $i$-th experimentally identified frequency.
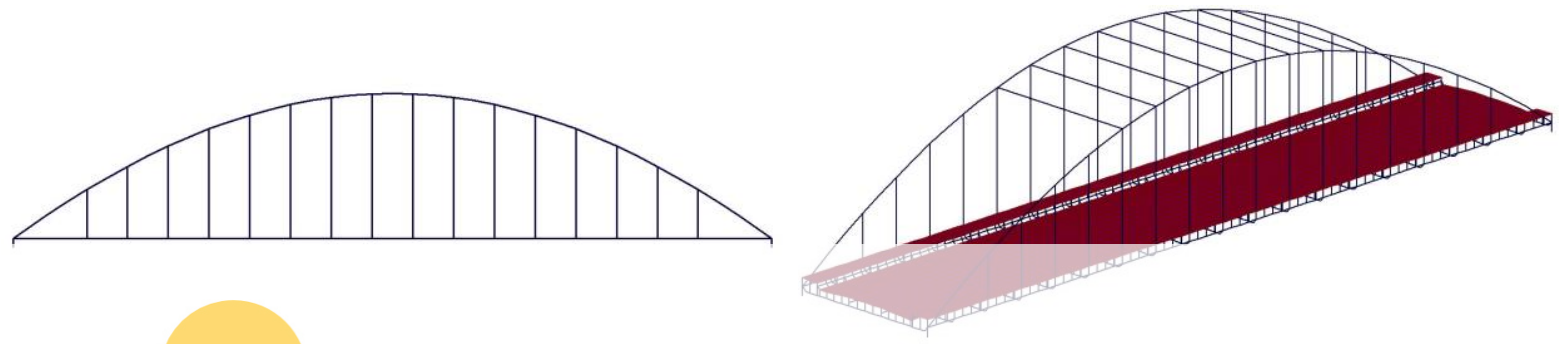

(a)

(b)

Figure 9: FE models: (a) 2D model, and (b) 3D model.
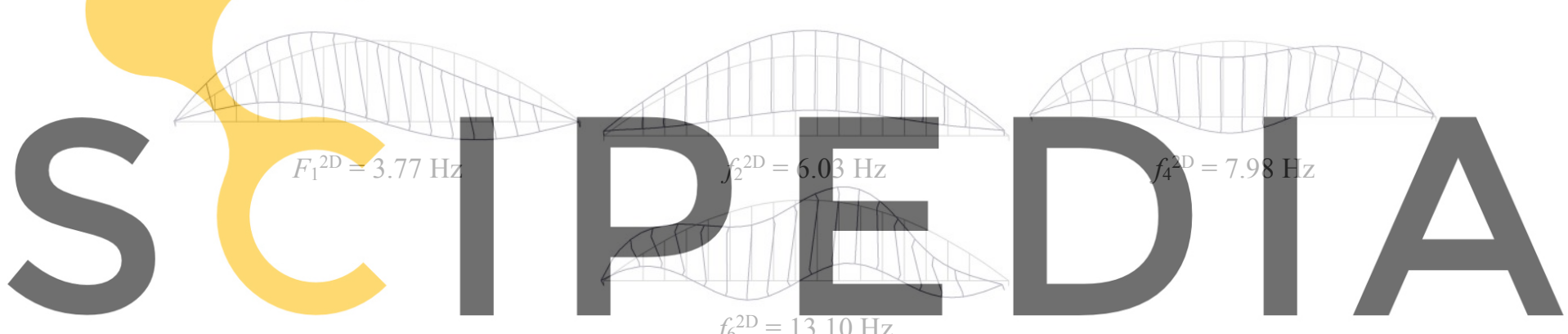

Figure 10: Vertical vibration modes of the updated 2D model

Register for free at https//WWW.scipedia.com to download the version without the watermark

The selected base values of the unknown parameters to apply the method are: $E_{\text {deck }}=40$ $\mathrm{GPa}, E_{\text {arch }}=35 \mathrm{GPa}, E_{\text {hanger }}=35 \mathrm{GPa}$ and $k_{\mathrm{s}}=2.0 \times 10^{6} \mathrm{kN} / \mathrm{m}$. The optimal values of those parameters are reported in Table 1, whereas the lower mode shapes of the updated 2D model are shown in Fig. 10. The comparison between the natural frequencies of the simplified model and the experimental ones is summarized in Table 2. It should be noticed that, despite the simplified nature of the 2D model, a good correlation is obtained in terms of both natural frequencies and mode shapes (Fig. 10): in terms of frequency discrepancy (defined as $\left.\Delta f_{\mathrm{i}}=100 \cdot\left|f_{\mathrm{i}}^{\text {exp }}-f_{\mathrm{i}}^{\mathrm{FEM}}\right| / f_{\mathrm{i}}^{\text {exp }}\right)$, the maximum and average discrepancy turned out to be $1.29 \%$ and $0.36 \%$, respectively (Table 2 ).

Furthermore, since the 2D model was mainly established to obtain a quick prediction of the results of static load tests, Fig. 8c exemplifies the match between predicted and measured displacements in the second load condition performed on Span 01.

After the full-scale tests, the numerical 3D model was developed. In this model 1980 beam elements were used to represent the longitudinal and transversal beams, the arches and the vertical hangers, whereas 1184 shells were used to simulate the concrete slab. The arches and the vertical hangers were modeled according to the available geometric survey, and 
furthermore, eight transversal beams were added to connect the top part of the arches. The deck was modeled as a grid of beams with four longitudinal beams, sixteen transverse beams (one for each vertical hanger) and an upper concrete slab $0.20 \mathrm{~m}$ thick. An equivalent section equal to $0.35 \times 0.80 \mathrm{~m}^{2}$ was attributed to the slab transversal beams. Concerning the boundary conditions, the model was considered as simply supported in longitudinal and transversal directions, while vertical springs were added to simulate the vertical deformability of pier and abutment of Span 01.

Similarly to the 2D model, the weight per unit volume and the Poisson's ratio of the reinforced concrete was assumed equal to $25 \mathrm{kN} / \mathrm{m}^{3}$ and 0.20 , respectively. The structural parameters selected in the updating procedure are: the Young's modulus of the two edge girders ( $\left.E_{\text {girder }}\right)$, the Young's modulus of the grid $\left(E_{\text {grid }}\right)$, the Young's modulus of the arches $\left(E_{\text {arch }}\right)$, the Young's modulus of the hangers $\left(E_{\text {hanger }}\right)$ and the constant $\left(k_{\mathrm{s}}\right)$ of the vertical springs supporting the span. Table 1 summarizes the optimal estimates of the updating parameters, whereas the mode shapes of the updated 3D model (corresponding to the experimental ones, see Fig. 6) are shown in Fig. 11. The comparison between the natural frequencies of the model and the experimental ones is reported in Table 2.

The inspection of Fig. 11 and Table 2 highlights an excellent correlation between the optimal 3D model and the experimental results, with the average and maximum frequency discrepancy being equal to $1.61 \%$ and $3.52 \%$, respectively; furthermore, Figs. 6 and 11 shows a fairly good correspondence of mode shapes, as well.

Finally, the analysis of results in Table 1 suggests that the updated parameters of the 2D and 3D models exhibit a fairly
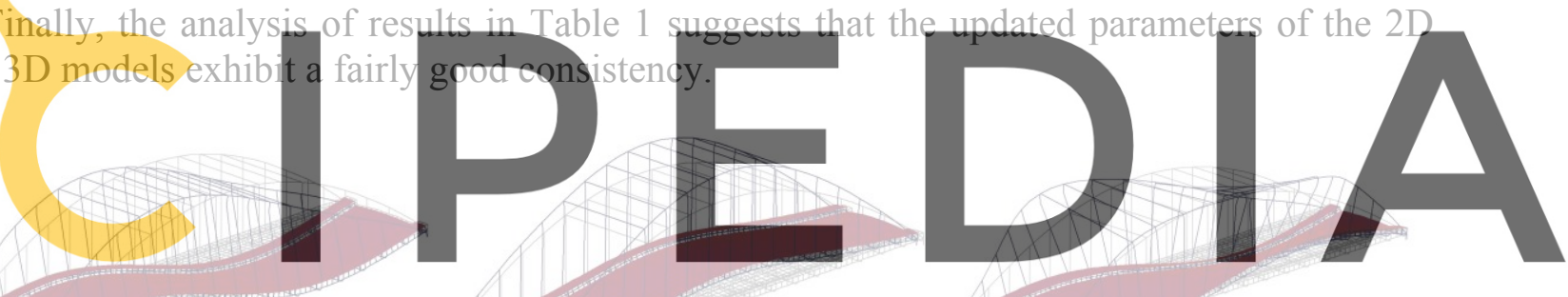

Register for free at https//www.scipedia.com to download the version without the watermark

$F_{1}{ }^{3 \mathrm{D}}=3.64 \mathrm{~Hz}$

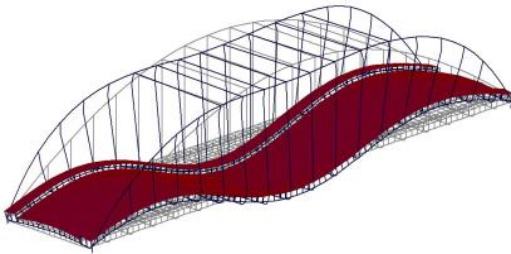

$F_{4}{ }^{3 \mathrm{D}}=7.89 \mathrm{~Hz}$ $f_{2}^{3 \mathrm{D}}=6.12 \mathrm{~Hz}$

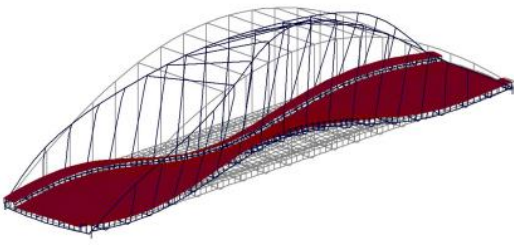

$f_{5}{ }^{3 \mathrm{D}}=9.13 \mathrm{~Hz}$

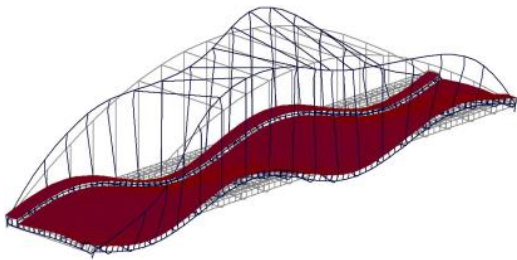

$f_{7}^{3 \mathrm{D}}=17.03 \mathrm{~Hz}$ $f_{3}^{3 \mathrm{D}}=7.02 \mathrm{~Hz}$

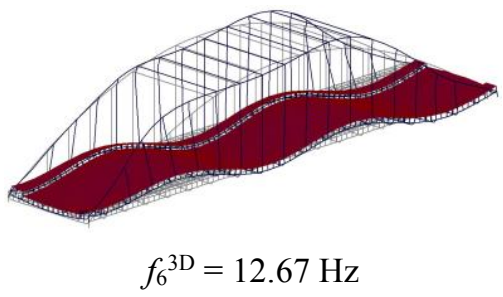

Figure 11: Vertical and torsion vibration modes of the updated 3D model. 
Table 1: Optimal structural parameters of 2D and 3D models

\begin{tabular}{|c|c|c|}
\hline Parameter & 2D model & 3D model \\
\hline $\mathrm{E}_{\text {deck }}(\mathrm{GPa})\left\{\begin{array}{c}\mathrm{E}_{\text {girder }} \\
\mathrm{E}_{\text {grid }}\end{array}\right.$ & 44. & $\begin{array}{l}42 . \\
35 .\end{array}$ \\
\hline$E_{\text {hanger }}(\mathrm{GPa})$ & 31. & 28. \\
\hline $\mathrm{E}_{\text {arch }}(\mathrm{GPa})$ & 36. & 42. \\
\hline $\mathrm{k}_{\mathrm{s}}(\mathrm{kN} / \mathrm{m})$ & $1.69 \times 10^{6}$ & $2.20 \times 10^{6}$ \\
\hline
\end{tabular}

Table 2: Comparison between experimental and numerical (2D and 3D updated model) frequencies

\begin{tabular}{rcccc}
\hline \multirow{2}{*}{$f^{\exp }(\mathrm{Hz})$} & \multicolumn{2}{c}{ 2D model } & \multicolumn{2}{c}{ 3D model } \\
\cline { 2 - 5 } & $f^{\mathrm{FEM}}(\mathrm{Hz})$ & $\Delta f(\%)$ & $f^{\mathrm{FEM}}(\mathrm{Hz})$ & $\Delta f(\%)$ \\
\hline \hline 3.772 & 3.774 & 0.05 & 3.639 & 3.52 \\
6.030 & 6.025 & 0.08 & 6.123 & 1.54 \\
7.019 & - & - & 7.019 & - \\
7.874 & 7.975 & 1.29 & 7.889 & 0.19 \\
8.972 & - & - & 9.127 & 1.73 \\
13.100 & 13.096 & 0.03 & 12.667 & 3.21 \\
17.210 & - & - & 17.029 & 1.06 \\
\hline \multicolumn{5}{c}{$\Delta f=100 \cdot \mid\left(f^{\exp }-f^{\mathrm{FEM}}\right) / f^{\exp }$}
\end{tabular}

\section{CONCLUSIONS}

The paper focuses on the preliminary structural assessment of the Brivio bridge. After the maintenance intervention performed on one pier, an extensive investigation of the bridge was carried out, including documentary research, visual inspection and geometric survey of each span, full-scale load tests, ambient vibration tests and FE models development. Based on the results presented in the paper, the following conclusions can be drawn:

- The historic research has provided valuable information on structural details and changes occurred to the structure;

- The visual inspection and the on-site geometric survey has provided information about the current geometry and heath state of the bridge;

- 7 vibration modes were identified from ambient vibration tests in the frequency range 0 $20 \mathrm{~Hz}$;

- The collected information allowed the development and validation of $2 \mathrm{D}$ and $3 \mathrm{D} \mathrm{FE}$ models;

- The calibrated 2D model was successfully used to predict the vertical displacements measured in load tests (that, in turn, demonstrated a regular behavior of the bridge).

The investigation herein presented turned out to be of utmost importance in enhancing the knowledge of the bridge structural behavior. However, further investigation (involving coring tests of materials and continuous dynamic monitoring) have been recently scheduled.

Acknowledgements. The support of the Province of Lecco is gratefully acknowledged. The authors would like to thank M. Cucchi (LPM, Politecnico di Milano) for the assistance in conducting the field tests. 


\section{REFERENCES}

[1] Gentile, C. Modal and structural identification of a RC arch bridge. Struct. Eng. Mech. (2006) 22(1): 53-70.

[2] ICOMOS/ISCARSAH Committee. Recommendations for the analysis, conservation and structural restoration of architectural heritage (2005). https://www.icomos.org/en/documentation-center.com.

[3] Zonno, G., Aguilar, R., Boroschek, R. and Lourenço, P. B. Analysis of the long and shortterm effects of temperature and humidity on the structural properties of adobe buildings using continuous monitoring. Eng. Struct. (2019) 196: 109299.

[4] Saisi, A., Gentile, C. and Ruccolo, A. Continuous monitoring of a challenging heritage tower in Monza, Italy. J. Civ. Struct. Health Monit. (2018) 8(1): 77-90.

[5] Deger, Y., Cantieni, R. and Pietrzko, S. Modal analysis of an arch bridge: experiment, finite element analysis and link. In proceedings-spie the international society for optical engineering (1994), pp. 425-425

[6] Sena-Cruz, J., Ferreira, R. M., Ramos, L. F., Fernandes, F., Miranda, T. and Castro, F. Luiz Bandeira bridge: assessment of a historical reinforced concrete (RC) bridge. Int. J. Archit. Herit. (2013). 7(6): 628-652.

[7] Türker, T. and Bayraktar, A. Structural safety assessment of bowstring type RC arch bridges using ambient vibration testing and finite element model calibration. Measurement (2014) 58: 33-45.

[8] Santarella, L. and Miozzi, E. Italian bridges in reinforced concrete (in Italian). Hoepli, Milan (1924).

[9] Decreto Ministeriale 10 Gennaio 1907 (in Italian), Gazzetta Ufficiale 2 Febbraio 1907 n.28 (1907).

[10]Ferrari, R., Froio, D., Rizzi, E., Gentile, C. and Chatzi, E.N. Model updating of a historic concrete bridge by sensitivity-and global optimization-based Latin Hypercube Sampling. Eng. Struct. (2019) 179: 139-160.

[11]Brincker, R., Zhang, L.M. and Andersen, P. Modal identification of output-only systems using frequency domain decomposition. Smart Mater. Struct. (2001) 10(3): 441-445.

[12]Douglas, B.M., Reid, W.H. Dynamic tests and system identification of bridges. ASCE J. Struct. Eng. (1982) 108(10): 2295-312. 